\title{
MODELING A GARMENT MANUFACTURER'S CASH FLOW USING OBJECT-ORIENTED SIMULATION
}

\author{
José A. Sepúlveda \\ Department of Industrial Engineering and Management \\ Systems, University of Central Florida \\ Orlando, FL 32816, U.S.A.
}

Haluk M. Akin

Atakoy 2. Kisim J-39/9

Bakirkoy, Istanbul, 34158, TURKEY

\begin{abstract}
Garment manufacturers usually work with a short vision of the demand to come in the following months. So they want to borrow as little as possible while still making a good profit at the end of the year. This study models a garment manufacturer's cash flow with the objective of finding scenarios where the company will be employing a low level of its credit-line and still be making a reasonable profit. To model our problem, we use Silk, an object-oriented simulation library in Java. Input data from a small-sized garment manufacturing company is used to build and test the model. A model where the manufacturer can test decisions like investing on opening new job shops, changing the production scheduling heuristics, or changing the payment agreements with suppliers and an example usage of the simulation are presented.
\end{abstract}

\section{INTRODUCTION}

Modeling a garment manufacturer is a very complex task. Many hard-to-predict variables need to be considered during the process. Most of the time the manufacturer has a very dim idea of the near future demand, so the manufacturer wants to be ready for the worst. Although the manager wants to reach the best profit possible, he or she also wants to work with less risk, meaning less amount of employed credit-line.

Within this study we model a garment manufacturer's cash flow over a one year period. Our objective will be creating a model which would help the manufacturer to decide

- The investments to make

- The production planning heuristic to use

- The payment options to be used with suppliers.

At the end of this study, in order to demonstrate the capabilities of the model, we will implement some of these decision variables within the model and see the effects of changes made upon them. The following will be our response variables:

- Average yearly profit

- Maximum loan used within the year

- Average daily loan

- Tardiness of orders

- Lateness of orders.

\subsection{Background}

Garment manufacturing requires many hard decisions due to its complex nature with hard-to-predict inputs and outputs. What makes this industry different from other industries is that it is labor-intensive. So far the advancements in computer aided manufacturing have not been able to mechanize the main processes of garment manufacturing. Sewing is one major example of a process that has not been automated. As a result, productivity improvement has been slow in comparison to other industries (Lin, Kincade and Warfield 1994). This reliance on intensive manpower creates a new challenge every time an order with a new design is accepted by the manufacturer. It is hard for the foreman to predict the production time of an order before beginning work on the order. Most of the time, it is only by the end of the first work day when the foreman can foresee how long the production will take.

The amount of labor in the final garment cost is between 30-50\% for U.S. garment manufacturers (Lin, Moore, Kincade and Avery 2002). As a natural result, the industry shifts from the developed countries to emerging countries.

Lin, Moore, Kincade, and Avery's (2002) study also shows that more than half the apparel products sold in the U.S. come from countries with low average wages.

Figure 1 (Textiles Conference 2003) shows the share of emerging countries over textile and apparel exports between 1962 and 1997.

The bonds between these brands and manufacturers are most of the time only on-order bases. Brands do not invest in manufacturers' assets, so they can always and easily 


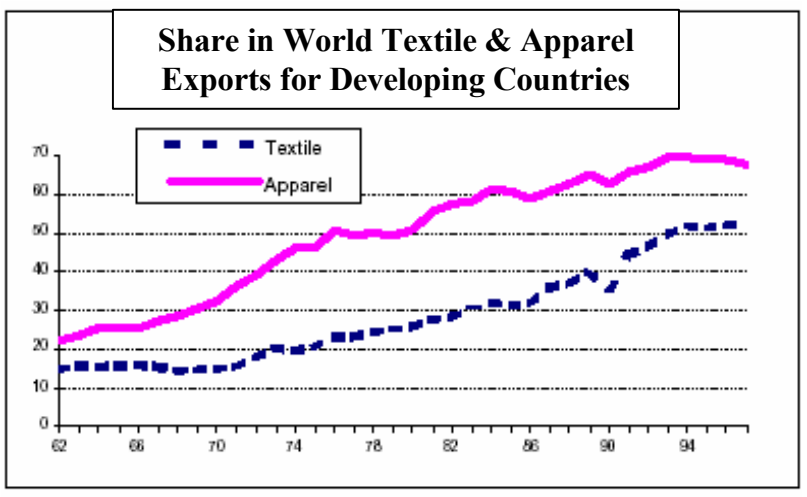

Figure 1: Share of Developing Countries in World Textile and Apparel Exports (Textiles Conference 2003)

take the liberty to shop for lower price offering manufacturers in today's global environment. Therefore, the manufacturers can hardly forecast the orders they will receive in the near future. This uncertainty encourages them to work with flexible methods like using subcontractors to manufacture parts of their orders.

Bowers and Agarwal (1993) divide garment manufacturers into two types:

- Style shops

- Basic apparel manufacturers.

Style shops are manufacturers which work on frequently changing designs. Although they charge more than basic apparel manufacturers, they have to deal with higher setup costs. Their product lines change seasonally, so the demand forecasting is difficult and sometimes they have to purchase new machinery to adapt to new designs. On the other side, basic apparel manufacturers charge less for the orders they manufacture and they incur less costs in comparison to style shops. Basic apparel manufacturers have the ability to use historical data to predict future demand.

Lin et al. (1994) define the relation between style change frequency and production volume as follows:

- Manufacturers that work with a staple product line have $0-1$ changes per season, and they can be considered as mass producers.

- Manufacturers that work with a semi-staple product line have 2-3 changes per season, and they can be considered as mid-volume producers.

- Manufacturers that work with a fashion product line have 4-6 changes per season, and they can be considered as low volume producers.

- Manufacturers that work with a high-fashion product line have more than 6 changes per season, and they can be considered as special producers.

Since Lin et al. (1994) conducted this research, many brands started to produce more than 6 seasons a year, so we could suggest that these days most of the manufacturers are working with fashion and high-fashion product lines.

The kind of garment manufacturer we are focusing on in the context of our study will be a high fashion style shop where many different styles come in every season for production. As we showed above, this is the kind of company which gets the lowest volume per order, which changes styles more than other manufacturers, and which therefore deals with more uncertainty in comparison to the other types of shops.

Since there is a high level of uncertainty in the number and style of orders to expect, style shops often prefer using subcontractors on some parts of their orders. These subcontractors reduce the financial burdens of the manufacturer. If the company gets into a bad season, it will not have to pay the wages of permanent workers.

An alternative to subcontractors can be dynamically decreasing and increasing the number of workers. However, Bowers and Agarwal (1993) suggest that this is equally as costly as increasing the number of permanent employees because it creates declines in efficiency, quality, and throughput. Plus if a company decides to lay off workers, it might be subject to compensation payments, which many times might prove very costly.

Another problem is the reduced lead time in the industry. In 1993, Bowers and Agarwal (1993) defined the average lead time of garment manufacturers as 6 weeks from cutting to shipping. However, in today's competitive environment, even 3 weeks is a long time from cutting to shipping.

\subsection{Problem Statement}

In summary we can outline the main complexities of garment manufacturing as follows:

- Labor-intensive

- Small sized orders

- Frequently changing styles

- Less repetition in orders

- Shorter lead times.

When these problems are examined holistically, it is apparent that there is no single solution method to improve the garment manufacturers who work with frequently changing styles. They need to be as ready as possible for unexpected events.

In this study we will develop a model for the manufacturer to use in the decision making processes like:

- Deciding to accept or reject an order

- Deciding on how and how much to finance

- Deciding whether to use subcontractors or not

- Deciding on how to do the production planning.

This kind of model certainly needs to run fast and produce accurate results. Since many factors will be involved in 
the decision making, the model needs to be flexible too. Therefore, we'll use Silk for modeling this system (Healy and Kilgore 1998). Silk is an object-oriented discrete-event simulation library based on the Java programming language.

\subsection{Significance of the Problem}

The significance of this problem comes from the complexity of this system for the focus on cash flow. Although the system is complex, our model will try to model most of the important aspects of the simulation, making as few assumptions as possible. All the conducted research for garment manufacturers focused on some specific parts of the garment manufacturing process. Optimizing the throughput of the manufacturer has been in focus several times before. However, we will consider the performance measures which really matter to the manufacturer: "the risk of over exposure to credit" and "the profit."

In the end we will also consider yearly profit as a performance measure. So we will try to find a scenario where an acceptable profit is made while a lower level of risk is employed.

\section{LITERATURE REVIEW}

When compared to other industries, garment manufacturing has received little academic attention. Therefore, there are only a handful of scientific articles and books that have been written for this field.

A very good article about production planning in garment manufacturing was written by Bowers and Agarwal (1993). They first define the framework of garment manufacturing whilst emphasizing the difference between style based production and basic dress manufacturing. Then the authors come up with a solid hierarchical production planning methodology. An important aspect of this article is that the authors re-optimize the production plan every week for the following 4-6 weeks.

Another good article was written by Forsyth and Porter (2000), where the authors define and examine the problems of UK garment manufacturers. Although the article is written specifically for a UK company, the characteristics of that company are very similar to other garment manufacturers around the world.

Another production planning and scheduling method was developed by Chen, Racine and Swift (1992). The authors use an analytical model for the daily productionscheduling problem and solve it with a practical solution procedure.

There are also a few studies that use simulation to solve garment manufacturers' production problems. One of these studies examines the trouser manufacturing process of garment manufacturers (Rosser, Sommerfeld and Wayne 1991). The authors come up with a detailed simulation of a trouser manufacturing shop.
Another study that deals with the manufacturing process in detail was done by Hashemipour and Kayaligil (1999). They simulate a garment manufacturer in order to improve the throughput rate and delivery performance by changing the labor shifting and lot sizing parameters. Their study simulates the manufacturer at the level of work-stations.

De Toni and Meneghetti (2000) concentrate on the production planning side of the industry, but this time they consider the network of firms that works for the same orders. The authors make use of both mixed-integer programming and simulation to see the effects of production planning. In the end they find that production time is the most important aspect of planning. They also support their findings with a cash flow approach.

In another production-focused article, authors go deeper than the previous articles and develop a model taking into account the operators' efficiencies (Racine, Chen and Swift 1992). The main problem the authors consider is the changing of styles in the job shop. This creates training needs, which certainly reduces the capacity of the production.

Lin, Kincade and Warfield (1994) put the focus on the productivity of the apparel industry in their article "Productivity and production in the apparel industry." Their survey statistically proves that productivity is directly proportional to production volume and is inversely proportional to the frequency of style change.

\section{GARMENT MANUFACTURING PROCESS}

The kind of company which we model in this study works through the following steps.

1. Receive an order: The company receives an order. The manager evaluates it and decides to accept or reject it. In our case, we will assume that all orders will be feasible and the manager will accept all of them (even if the production is very busy during that period). An order is considered to be feasible as long as it does not create a financial loss for the company.

2. Order fabric: The manager finds an appropriate fabric on the market and orders it. Fabric is delivered in the next 3 to 5 weeks.

3. Cut fabric: The fabric cutting process starts with spreading the fabric over a long rectangular table (at least 10 yards long and 1.5 yards wide). If the fabric is an easy-to-cut fabric, then 50-100 plies of fabric might be spread for one cut. If the fabric is a hard-to-cut fabric (for instance, silk) then 20-50 plies would be spread for one cut. Fabric cutting is rarely a bottleneck for the company, so we will assume a fixed production rate for the cutting process. However, fabric cutting is a very delicate process, as there is no way to go back after the fabric is cut. So the company never outsources the cutting process to prevent irreversible defects. 
4. Sew garment: After the fabric is cut, the manufacturer starts sewing the garment from cut fabric. This process either can be done in-house or can be assigned to subcontractors. In our baseline simulation we will assume that an order is assigned to a subcontractor if and only if the in-house sewing shop will be busy in the following 5 calendar days. Otherwise the order is queued for in-house sewing.

5. Wash garment (optional): Depending on the customer's requests, some orders are washed. Almost all manufacturers around the world outsource this process.

6. Package garments: After the garments are sewn and washed (optional), they are ironed and packaged. This process can be done in-house or can be assigned to subcontractors. For the baseline simulation, sewing production planning heuristic will be used. If the in-house packaging shop is going to be busy in the next 5 days, then the order is assigned to a subcontractor.

7. Ship: As soon as the garments are packaged, the order is shipped to the customer through international transportation companies.

\section{UML MODEL}

After defining the process of garment manufacturing, we have designed a model of this system using the Unified Modeling Language (UML).

Figure 2 shows the relationship between three important classes of our model. It can be seen that one customer can have more than one order associated with it. Also one order can have more than one suborders associated with it. This means that a customer can have more than one order within our model. However an order can only have one customer. The same thing applies to suborders too. An order can have several suborders. However, a suborder belongs to only one order.
This figure also shows us some important parameters that are held within the suborder class:

- Quantity: Shows the number of pieces in a suborder

- Due date: The latest day on which the suborder needs to be shipped

- Unit price: Unit price of pieces in that suborder

- Arrival time: The day this suborder was generated

- Fabric time: The time it will take to produce this suborder's fabric.

Figure 3 shows the activity diagram for the processing of a suborder by a subcontractor.

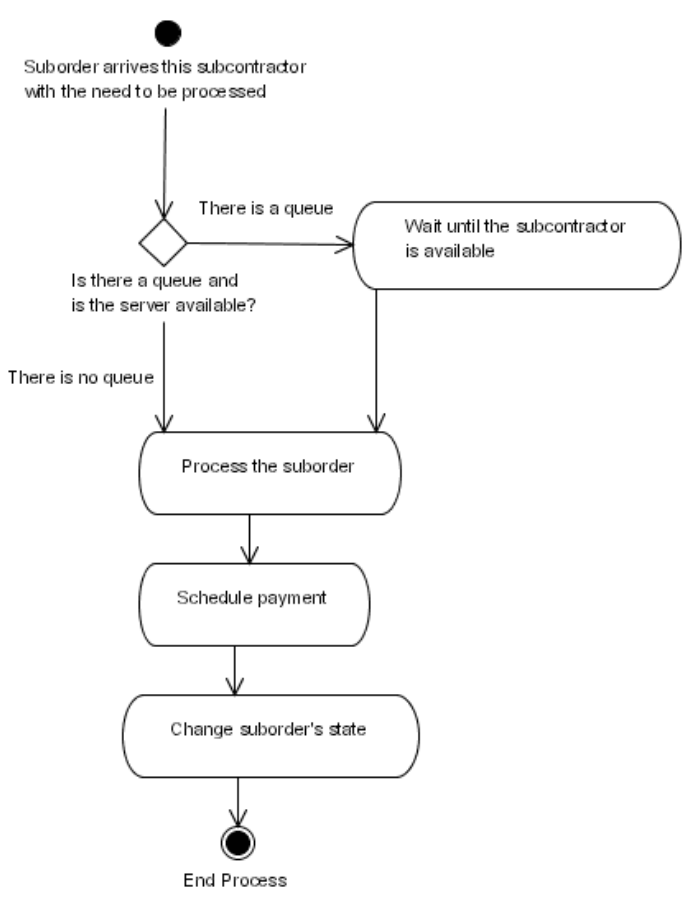

Figure 3: Activity Diagram for the Processing of Suborder by a Subcontractor

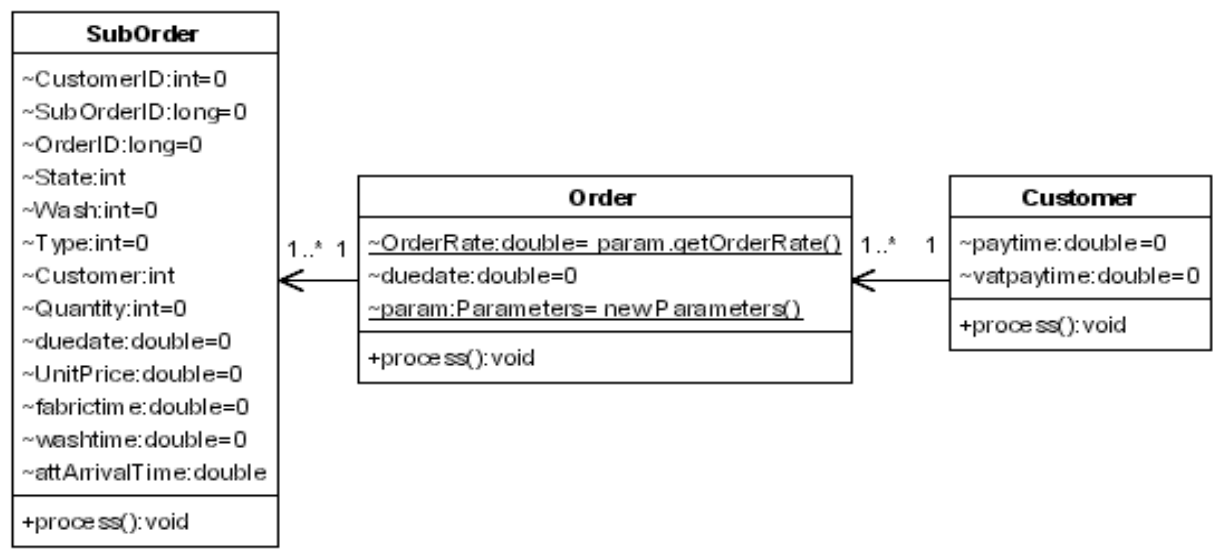

Figure 2: Relationship between Suborder, Order, and Customer Classes 
As we can see in the activity diagram a suborder arrives to the subcontractor and checks if there is a queue. If there isn't one and the subcontractor is available, it is processed. Otherwise, it is queued until the subcontractor is idle. After the processing is done, the subcontractor sched ules a payment with the company and changes the suborder's state. According to its new state, the suborder will be headed to a new process within the model.

Figure 4 shows the states of a subcontractor. A subcontractor can take two main states. One is being idle and the other is processing a suborder.

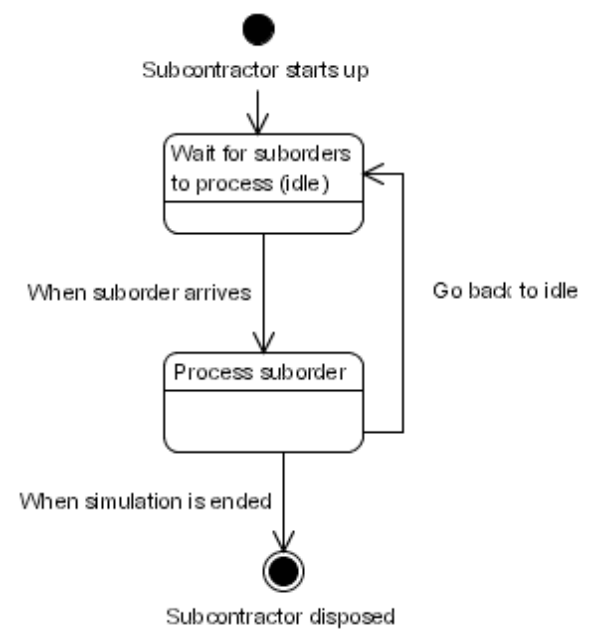

Figure 4: State Diagram of a Subcontractor

Figure 5 shows the sequence diagram for our model. It can be seen that the flow of action starts with a customer's generation of an order. Then the order is evaluated by the manager, and when it is accepted, the order creates its suborders. Then suborders start being processed.

Actors like fabric factory, sewing, packaging, etc. call the payments class and schedule a payment in return for their services. However, actors like modeling department, cutting department, etc. do not schedule payments, as they are part of the company and their services are paid in the form monthly wages.

\section{SIMULATION}

In this section we will discuss the technical details of the simulation itself.

\subsection{Run Length}

We decided to work on a 1 year simulation. We simulated one warm-up year followed by another year from which we collected data for output analysis.

\subsection{Replications}

To decide the number of replications necessary for our simulation, we simulated our model with the original con- ditions for 200 replications of 2 years. Every replication took around 20 seconds to simulate on a $512 \mathrm{MB}$ and P42.20GHz computer.

With 100 replications the averages and half-widths of our main performance criteria converged to reasonable values, so we decided to use 100 replications.

\subsection{Scenarios}

To illustrate the use of this model, we have selected three parameters.

Our first parameter was deciding to open or not to open an in-house sewing job. If it is opened, the job shop creates a monthly fixed cost of $\$ 24,400$, which is due the last business day of every month. The decision to schedule an order to the in-house sewing shop relies on the business of the job shop. If the shop is going to be available in the following five days, an order that is ready to be sewn will enter the queue for the in-house sewing shop. If not, it will be directed to a sewing subcontractor. This is only a simple production scheduling example; more complicated scheduling algorithms can easily be implemented.

The second parameter was opening an in-house packaging job shop or not. If opened, the shop creates a fixed cost of $\$ 11,900$, which is due the last business day of every month. The decision to schedule an order to the in-house packaging shop will rely on the business of the job shop. If the shop is going to be available in the following five days, an order that is ready to be packaged enters the queue for the shop. If not, it is directed to a packaging subcontractor.

Again, a more complex production scheduling algorithm can be implemented here too.

The third parameter is about the payment schedule of fabrics. In the original scenario, the company pays the fabric's bill in 60 days. If the company decides to pay the bill in 30 days, the fabric factories are willing to offer a $3 \%$ discount. So, we'll decide to accept this discount payment scheme or not. A summary of the parameters can be seen below:

- In-house sewing:

- 0: Closed

- 1: Open

- In-house packaging:

- 0: Closed

- 1: Open

- Advance fabric payment:

- 0: Paid in 60 days

- 1: Paid in 30 days

Table 2 summarizes the scenarios.

\section{RESULTS}

In terms of lateness, all the scenarios where we have the inhouse sewing open resulted with a low lateness average. Al- 


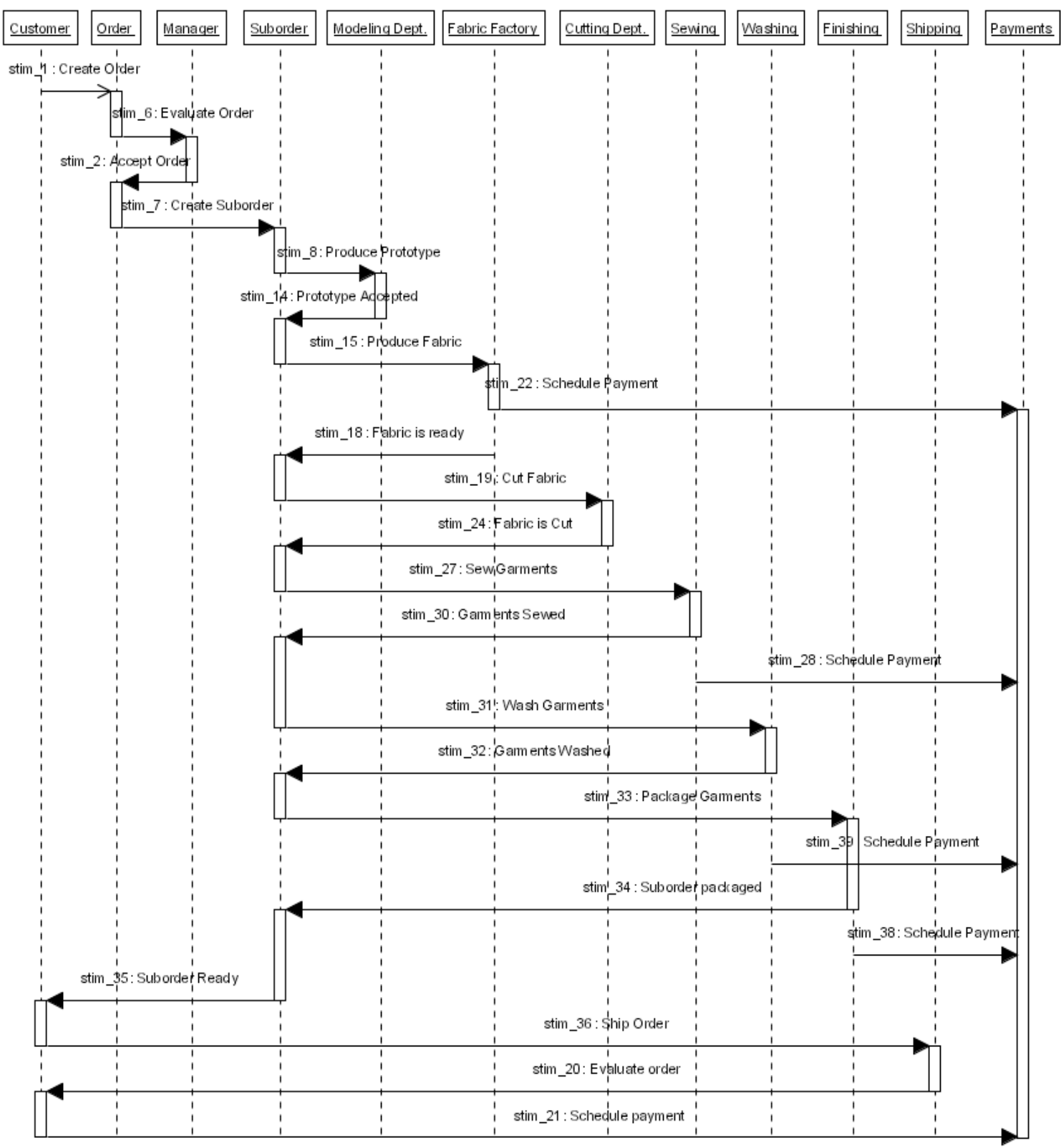

Figure 5: Sequence Diagram

Table 2: Scenarios

\begin{tabular}{cc}
\hline Scenario Number & $\begin{array}{c}\text { Parameters (In-house sewing, } \\
\text { In-house packaging, } \\
\text { Advance fabric payment) }\end{array}$ \\
\hline 1 & $(0,0,0)$ \\
2 & $(0,0,1)$ \\
3 & $(0,1,0)$ \\
4 & $(0,1,1)$ \\
5 & $(1,0,0)$ \\
6 & $(1,0,1)$ \\
7 & $(1,1,0)$ \\
8 & $(1,1,1)$ \\
\hline
\end{tabular}

though some of them resulted in higher tardiness values, that indicates that our production scheduling heuristic needs adjustments. In our heuristic we serve orders on the first come first served basis. However, if we implemented a weighted tardiness approach (Table 3), then the average tardiness values would have been closer to 0 on the positive side, and average lateness values would have been closer to 0 on the negative side. The half-width is for $90 \%$ confidence interval.

When we close in-house sewing, lateness values start getting higher, around 3 days on average. This is obviously something the manufacturer doesn't want. What we understand from this is that they should considering 
working with an additional sewing subcontractor. Further analysis would have shown us what size of sewing subcontractor is necessary.

In Table 4 we can see that in terms of the profit, the best options would be either keeping the system as it is $(0,0,0)$ or buying fabrics with $3 \%$ percent incentive $(0,0,1)$. It is worth noting that these options also create low daily loan averages.

Table 3: Tardiness and Lateness Results

\begin{tabular}{lrrr}
\hline Statistics & Scenario & Tardiness & Lateness \\
\hline Average & $(1,1,1)$ & 0.99 & -7.49 \\
Average & $(1,1,0)$ & 0.99 & -7.49 \\
Average & $(1,0,1)$ & 2.70 & -4.43 \\
Average & $(1,0,0)$ & 2.70 & -4.43 \\
Average & $(0,0,1)$ & 8.30 & 3.57 \\
Average & $(0,1,1)$ & 8.01 & 2.85 \\
Average & $(0,1,0)$ & 8.01 & 2.85 \\
Average & $(0,0,0)$ & 8.30 & 3.57 \\
Half-width & $(1,1,1)$ & 0.16 & 0.35 \\
Half-width & $(1,1,0)$ & 0.16 & 0.35 \\
Half-width & $(1,0,1)$ & 0.79 & 1.06 \\
Half-width & $(1,0,0)$ & 0.79 & 1.06 \\
Half-width & $(0,0,1)$ & 1.74 & 1.98 \\
Half-width & $(0,1,1)$ & 1.93 & 2.18 \\
Half-width & $(0,1,0)$ & 1.93 & 2.18 \\
Half-width & $(0,0,0)$ & 1.74 & 1.98 \\
St. Deviation & $(1,1,1)$ & 0.96 & 2.11 \\
St. Deviation & $(1,1,0)$ & 0.96 & 2.11 \\
St. Deviation & $(1,0,1)$ & 4.82 & 6.45 \\
St. Deviation & $(1,0,0)$ & 4.82 & 6.45 \\
St. Deviation & $(0,0,1)$ & 10.56 & 12.04 \\
St. Deviation & $(0,1,1)$ & 11.71 & 13.23 \\
St. Deviation & $(0,1,0)$ & 11.71 & 13.23 \\
St. Deviation & $(0,0,0)$ & 10.56 & 12.04 \\
\hline
\end{tabular}

Whilst praising these two options, we should also point to the high standard deviation. So when we suggest to the managers that these options will be better than the others, we won't be able to suggest that these profit suggestions have high preciseness. However, we will be able to suggest that under the same demand conditions these solutions would be better than others.

If the managers ask for a more robust solution where the standard deviation is lower, then the best solution would be either $(1,0,0)$ or $(0,1,0)$. These are also solutions where the company makes a good yearly profit around 80,000USD. Especially $(0,1,0)$ can be favored with its low loan level.

When we evaluate these results overall, one thing certainly comes up: opening up in-house sewing or in-house packaging facilities at those costs and daily production rates is not a good idea. It would be wise to come up with alternative solutions where either costs are lower or productivity is higher and see the results they create.

So overall we were able to come up with several performance measures for these 8 scenarios and we could see the trade offs between these scenarios. Making additional scenarios and trying to find the optimum solution was possible but unnecessary, as our objective was modeling the cash flow of this garment manufacturer and illustrating the use of this model.

Table 4: Financial Results

\begin{tabular}{|c|c|c|c|c|}
\hline Statistics & Scenario & $\begin{array}{c}\text { Daily } \\
\text { Loan } \\
\text { Average }\end{array}$ & $\begin{array}{l}\text { Maxi- } \\
\text { mum } \\
\text { Loan }\end{array}$ & Profit \\
\hline Average & $(1,1,1)$ & $\$ 29,407$ & $\$ 183,169$ & $\$ 22,912$ \\
\hline Average & 0) & 37,445 & $\$ 165,306$ & $-\$ 14,563$ \\
\hline Average & $(1,0,1)$ & $\$ 23,716$ & $\$ 168,026$ & $\$ 121,191$ \\
\hline Average & $(1,0,0)$ & $\$ 22,820$ & $\$ 137,798$ & $\$ 87,897$ \\
\hline Average & $(0,0,1)$ & $\$ 25,004$ & $\$ 167,077$ & $\$ 189,109$ \\
\hline Average & $(0,1,1)$ & $\$ 24,481$ & $\$ 161,265$ & $\$ 110,227$ \\
\hline Average & $0.10)$ & $\$ 23,333$ & $\$ 140,110$ & $\$ 76,904$ \\
\hline & & & $\$ 152,444$ & $\$ 159,0$ \\
\hline Half- & & 3 & 38 & $\$$ \\
\hline Half-w & ( & $\$ 5,793$ & $\$ 14,400$ & $\$ 22$, \\
\hline Half-width & $(1,0$, & $\$ 4,630$ & $\$ 18,067$ & $\$ 23,060$ \\
\hline Half-width & $(1,0,0)$ & $\$ 4,863$ & $\$ 16,316$ & $\$ 20,983$ \\
\hline Half-width & $(0,0,1)$ & $\$ 5,372$ & $\$ 19,107$ & $\$ 34,049$ \\
\hline Half-width & $(0,1,1)$ & $\$ 3,827$ & $\$ 14,586$ & $\$ 22,906$ \\
\hline Half-width & $(0,1,0)$ & $\$ 4,017$ & $\$ 14,588$ & $\$ 19,907$ \\
\hline Half-width & $(0,0$, & 4,728 & $\$ 18,989$ & \\
\hline & & & & $\$ 152,621$ \\
\hline St. I & $(1,1$ & 35,217 & $\$ 87,545$ & $\$ 137,24$ \\
\hline St. Dev. & $(1,0,1)$ & $\$ 28,148$ & $\$ 109,840$ & $\$ 140,193$ \\
\hline St. Dev. & $(1,0,0)$ & $\$ 29,566$ & $\$ 99,194$ & $\$ 127,570$ \\
\hline St. Dev. & $(0,0,1)$ & $\$ 32,662$ & $\$ 116,159$ & $\$ 207,004$ \\
\hline St. Dev. & $(0,1,1)$ & $\$ 23,265$ & $\$ 88,678$ & $\$ 139,256$ \\
\hline St. Dev. & $(0,1,0)$ & $\$ 24,424$ & $\$ 88,690$ & $\$ 121,026$ \\
\hline St. Dev. & $(0,0,0)$ & $\$ 28,744$ & $\$ 115,446$ & $\$ 177,994$ \\
\hline
\end{tabular}

\section{SUMMARY, CONCLUSIONS AND RECOMMENDATIONS}

\subsection{Summary}

Overall, within this study we succeeded in developing a valid object-oriented simulation, modeling the cash flow of a garment manufacturer. Our objective was to come up with results where the decision maker could see the trade off between the level of used credit line and the profit. Although the profit is the ultimate objective for any company, it is also necessary to employ as little of a credit line as possible too. This would give the managers two important opportunities. First, if any crisis occurs (internationally, nationally or even within the company) the company would face it with a lower level of risk. Second, if the company enters into a temporary bad season, it would have more credit line available to balance its cash flow.

\subsection{Conclusions}

In the end the model proved successful. We were able to show trade-offs between production scheduling models and 
payment incentives in terms of used credit and profit. If the managers want to try a new production schedule, they could see its good and bad sides in less than 2 hours. Also, if necessary they could easily modify or extend the model too.

\subsection{Recommendations}

Although this is a comprehensive model, it is hard to say it includes all important parameters of the garment manufacturer model. One that certainly needs further attention is the currencies these manufacturers work with. Many midsize garment manufacturing companies operating in developing countries make exports to both Europe and the United States. This means that these companies deal with three currencies at the same time: their own country's currency, the Euro and the United States Dollar. The fluctuations in these currencies affect the level of profit these companies make. So it would be good to see if there are ways to reduce the negative effects of these fluctuations.

Further experiments showed us that the financial results are affected by large sum payments made or received at the end of the year. To reduce the affects of these payments over variance it would be interesting to repeat the same simulation with longer run times but less repetitions. If future experiments could come up with more robust solutions where standard deviation is reduced, then this would make these models more attractive to decision makers.

\section{REFERENCES}

Bowers, M. R., and A. Agarwal. 1993. Hierarchical production planning: Scheduling in the apparel industry. International Journal of Clothing Science and Technology 5 (3/4): 36-43.

Chen, C., R. Racine, and F. Swift. 1992. A Practical Approach to the Apparel Production-Planning and Scheduling Problem. International Journal of Clothing Science and Technology 4 (2/3):9.

De Toni, A., and A. Meneghetti. 2000. The production planning process for a network of firms in the textileapparel industry. International Journal of Production Economics 65 (1):17-32.

Forsyth, H. L., and K. Porter. 2000. Production planning and control improvements in a small UK garment manufacturer; a case study. International Journal of Production Planning \& Control 11 (6).

Hashemipour, M., and S. Kayaligil. 1999. Labor shifting and lot sizing in garment manufacture: A simulation study. International Journal of Industrial Engineering-Theory Applications and Practice 6 (3):224-233.

Healy, K. J., and R. A. Kilgore. 1998. Introduction to SILK and Java-based simulation. In Proceedings of 1998 Winter Simulation Conference, ed. D. Meideros, E. Watson, J. Carson, and M. Manivannan, 327-334.
Institute of Electrical and Electronics Engineers, Piscataway, New Jersey.

Lin, S., D. H. Kincade, and C. Warfield. 1994. Productivity and production in the apparel industry. International Journal of Clothing Science and Technology 6 (1): 20-27.

Lin, S., M. A. Moore, D. H. Kincade, and C. Avery. 2002. Dimensions of apparel manufacturing strategy and production management. International Journal of Clothing Science and Technology 14 (1):46-60.

Racine, R., C. Chen, and F. Swift. 1992. The Impact of Operator Efficiency on Apparel Production Planning. International Journal of Clothing Science and Technology 4 (2/3): 18.

Rosser P.S., J. T. Sommerfled, and W. C. Tincher. 1991. Discrete-event simulation of trouser manufacturing. International Journal of Clothing Science and Technology 3 (2): 18-31.

Textiles Conference. 2003. Evolution of Trade in Textile and clothing trade world-wide trade figures and structural data. Brussels, 5-6 May 2003. Available online via http://trade-info.cec.eu.int/ textiles/conf_docs.cfm [accessed April 7, 2004].

\section{AUTHOR BIOGRAPHIES}

JOSÉ A. SEPÚLVEDA, Ph.D., P.E., is an Associate Professor in the Department of Industrial Engineering and Management Systems at the University of Central Florida in Orlando, Florida. He received an Ingeniero Civil Químico degree from the Universidad Santa María, Valparaíso, Chile, and MSIE, MPH, and Ph.D. (Industrial Engineering) degrees from the University of Pittsburgh. Dr. Sepúlveda is a registered Professional Engineer in Florida and Chile. Dr. Sepúlveda's major areas of research interest are object-oriented simulation, simulation optimization, risk analysis, catastrophe response, measuring and modeling training effectiveness, tasks scheduling in complex and risky environments, and applications of industrial engineering and simulation in health care. He has written two books and numerous publications. His email address is <sepulved@mail.ucf.edu>.

HALUK M. AKIN is studying towards his M.S. degree at the Industrial Engineering and Management Systems Department at the University of Central Florida. He received his B.S. degree from Yildiz Technical University, Istanbul in 2002. Prior to his MS education, he worked in the production planning department of a small sized garment manufacturing company. His e-mail address is <halukakin@tirol.com.tr 